\title{
KNOWLEDGE AND PERCEPTIONS OF SELF-MEDICATION PRACTICES IN AN URBAN COMMUNITY
}

\author{
VARGHESE SNEHA SUJA, SNEHA DUTTA, ANN MARY SWAROOP*
}

Department of Pharmacy Practice, Faculty of Pharmacy, M.S. Ramaiah University of Applied Sciences, Bengaluru, Karnataka, India. Email: annmary103@gmail.com

Received: 24 April 2019; Revised and Accepted: 08 June 2019

ABSTRACT

Objective: This study was conducted with the aim to assess the knowledge and attitude of self-medication practices among the residents of an urban community.

Methods: A cross-sectional, observational study was conducted among 270 participants for the duration of 6 months using a semi-structured questionnaire which consisted of the domains of knowledge and attitude. Logistic regression was used for drawing statistical inferences.

Results: The prevalence of self-medication was found to be $37.04 \%$. It was found that $73.33 \%$ of the respondents were aware of the term "selfmedication" and their major source for information was obtained through acquaintances (44.44\%). About $68.55 \%$ of the participants agreed that self-medication is a part of taking care of oneself and it needs to be encouraged. Overall, the participants had a good knowledge and positive attitude toward the practice of self-medication.

Conclusion: This study mainly focuses on improving the subjects' knowledge, thereby bringing changes in the attitude and practice toward disease management. Understanding the subjects' level of knowledge and attitude will enable a more efficient process for creating an awareness among the public to ensure its safe and responsible use.

Keywords: Self-medication, Knowledge, Attitude, Prevalence, Community.

(C) 2019 The Authors. Published by Innovare Academic Sciences Pvt Ltd. This is an open access article under the CC BY license (http://creativecommons. org/licenses/by/4. 0/) DOI: http://dx.doi.org/10.22159/ajpcr.2019.v12i8.33721

\section{INTRODUCTION}

Self-medication is an essential and fundamental element of selfcare [1]. The WHO defines self-medication practices as "the selection and use of medicines by individuals to treat self-recognized illness or symptoms" [2,3]. In other words, self-medication involves treating typical health issues with medicines which are labeled for use without medical supervision and is authorized as safe and effective [4].

In developing countries like India, many drugs are dispensed over the counter without a prescription [5]. This could be due to various factors such as socioeconomic status, easy availability of medicinal products, higher consultation costs, and long waiting hours in hospitals [6-8].

The growing trend of "self-care" has its own positive and negative aspects. In particular, the ordinary user will usually have no specialized knowledge of the concepts of pharmacology or of the particular characteristics of the medicinal product used [3]. It increases the probabilities of illicit use of drugs, drug dependency, and masks the signs and symptoms of underlying disease conditions. This could result in various complications including wastage of resources, increased resistance to pathogens, and serious health hazards such as adverse reactions, drug interactions, drug duplications, and prolonged suffering [9]. There is always a possibility of interaction between active ingredients and hidden excipients or hidden classes of drugs which can worsen the existing disease pathology [10]. In contrast, self-medication by individuals who agree to take responsibility and are careful is a resource-saving phenomenon to the health system. Self-medication is useful in treating minor ailments that do not require medical consultation, thereby reducing the pressure on medical services, particularly in the underdeveloped countries with inadequate health-care facilities [7].

The WHO emphasizes that self-medication must be appropriately communicated and controlled [11]. Although the practice of self- medication is challenging to eliminate, interventions can be made to discourage the indiscreet practice [12]. Positive and responsible approach toward self-medication practices are spreading throughout the world and it is recognized that responsible self-medication must be accompanied by appropriate health information [13]. Due to inadequate availability of literature regarding the distribution and use of OTC drugs at community level, little is known about self-medication practices [14]. Our study was conducted against this backdrop with the aim to assess knowledge and attitude toward the practice of self-medication among the residents of an urban community in Bengaluru.

\section{METHODS}

\section{Study design}

A cross-sectional, questionnaire-based observational study was carried out among the residents of an urban community in Bangalore to assess the knowledge and perception of self-medication practices. The inclusion criteria for the selection of participants were 18 years and above with or without comorbidities.

\section{Sample size}

The minimum sample size required for this study was calculated to be 230 with $95 \%$ confidence interval (CI) and with $5 \%$ relative precision [15].

\section{Ethical clearance}

The complete project was done in accordance with the permission granted by M. S. Ramaiah Ethics Committee.

\section{Study procedure}

Development of the questionnaire

To develop the questionnaire, articles published in the relevant fields were collected to frame the questions. The designed questionnaire was subjected for internal validation among the faculty members of 
Ramaiah University of Applied Sciences for their inputs regarding acceptance and relevance.

\section{Pilot study and validation of the questionnaire}

The internally approved questionnaire was subjected for external validation among selected participants ( $10 \%$ of the sample size). The response rate for validation of the questionnaire was evaluated in terms of percentages and documented. After 2 weeks, the same questionnaire (but questions were shuffled) was administered among the same participants and responses were recorded again. Documented results were compared to estimate the internal consistency of the questions in the questionnaire using Cronbach's alpha. A value of 0.74 was obtained demonstrating a good level of internal consistency.

\section{Administration of the validated questionnaire}

A self-developed, pre-validated questionnaire consisting of both openended and closed-ended questions was used. A briefing was given about the nature of the study and the procedure for completing the questionnaire was explained. Written informed consent was obtained from all the respondents before administering the questionnaire.

\section{Documentation and analysis}

Completed questionnaires were transcribed into suitably designed Google forms. Manual data were entered into Microsoft Excel and further analyzed using the Statistical Package for the Social Sciences Version 20.0. Logistic regression was used for drawing statistical inferences and $\mathrm{p}<0.05$ was considered statistically significant.

\section{RESULTS}

A total of 270 participants were assessed regarding their knowledge and attitude toward the practice of self-medication, of which $51.48 \%$ $(\mathrm{n}=139)$ were male and $48.52 \%(\mathrm{n}=131)$ were female. The mean age of the respondents was $36.5 \pm 16.4$ years. According to our findings, the majority of the participants were graduates $(61.8 \%)$ followed by postgraduates $(17.04 \%)$. The predominant occupational status of the participants in our study was private sector (38.15\%) followed by students $(22.23 \%)$ and homemakers $(17.41 \%)$. The prevalence of self-medication among the study participants was found to be $37.04 \%$. It was found that $73.33 \%$ of the subjects were aware of the term "self-medication" and their main source of information regarding the practice of self-medication was obtained through acquaintances (44.44\%) (Fig. 1 and Table 1). It was found that majority of the participants' preferred allopathic system of medicine (50.37\%). The study findings showed that the participants' knowledge regarding the duration of time safe to practice self-medication was for few days $(48 \%)$ followed by till the participants were relieved of symptoms $(28 \%)$. Most of the participants $(45.6 \%)$ found the practice of selfmedication to be safe, whereas $28.5 \%$ said that it was unsafe (Fig. 2). According to the knowledge of the participants, adults (80.74\%) were considered as the safest population to practice self-medication. It was found that $72.22 \%$ were aware of the side effects of the self-prescribed medicines. The participants were also aware of the complications of self-medication such as excessive drug usage (71.48\%), misdiagnosis (71.11\%), prolonged duration of use $(62.96 \%)$, drug interactions (57.41\%), polypharmacy (53.33\%), and incomplete course of therapy (52.59\%) (Table 2).

Table 3 shows the attitude of the respondents toward the practice of self-medication. The mean attitude score based on the responses obtained was calculated to be 10 of 14 , thus concluding that the subjects have a positive perception regarding the practice of self-medication. Risk estimates quantified the association between the respondents knowledge regarding the practice of self-medication with their attitude toward the same. It was found that respondents who had a positive attitude with regard to the practice of self-medication had knowledge regarding the side effects of self-prescribed medicines $(\mathrm{OR}=0.21,95 \%$ CI [0.051-0.939], p: 0.026). Respondents were also familiar to the fact that self-medication practice could result in excessive drug usage (p: 0.047) and prolonged duration of drug use (p: 0.050)

Table 1: Source of information for the subjects' regarding self-medication

\begin{tabular}{lll}
\hline Response & Frequency & Percentage \\
\hline Acquaintances & 120 & 44.44 \\
Media & 66 & 24.44 \\
Formal education & 60 & 22.22 \\
Previous prescription & 47 & 17.41 \\
Health facilities & 42 & 15.55 \\
\hline
\end{tabular}

Table 2: Knowledge of the subjects' regarding the complications associated with self-medication practices

\begin{tabular}{llll}
\hline \multirow{2}{*}{ Response } & \multicolumn{2}{l}{ Percentage } & \\
\cline { 2 - 4 } & Yes & No & Unaware \\
\hline Misdiagnosis & 71.11 & 7.78 & 21.11 \\
Excessive drug usage & 71.48 & 10.74 & 17.78 \\
Prolonged duration of use & 62.96 & 9.63 & 27.41 \\
Drug interactions & 57.41 & 10.00 & 32.59 \\
Polypharmacy & 53.33 & 9.63 & 37.04 \\
Incomplete drug therapy & 52.59 & 15.93 & 31.48 \\
\hline
\end{tabular}

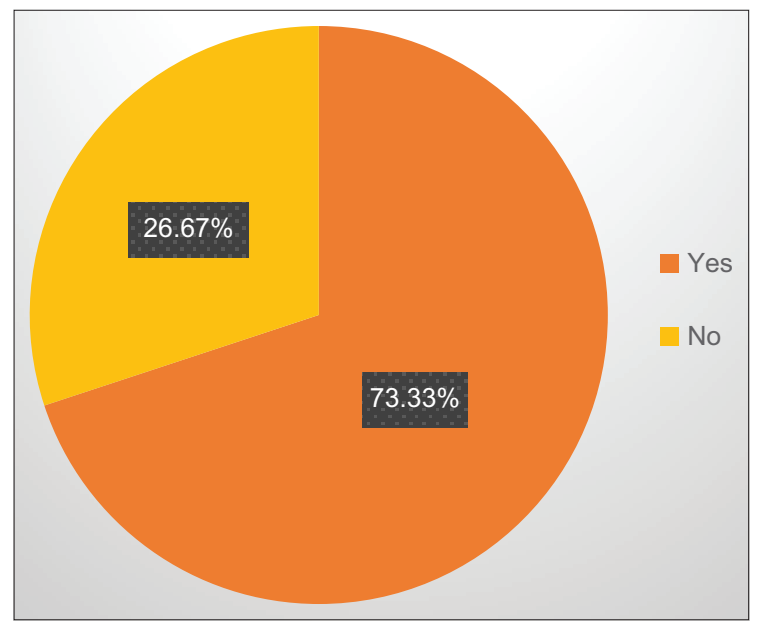

Fig. 1: Awareness of the subjects regarding the term "selfmedication"

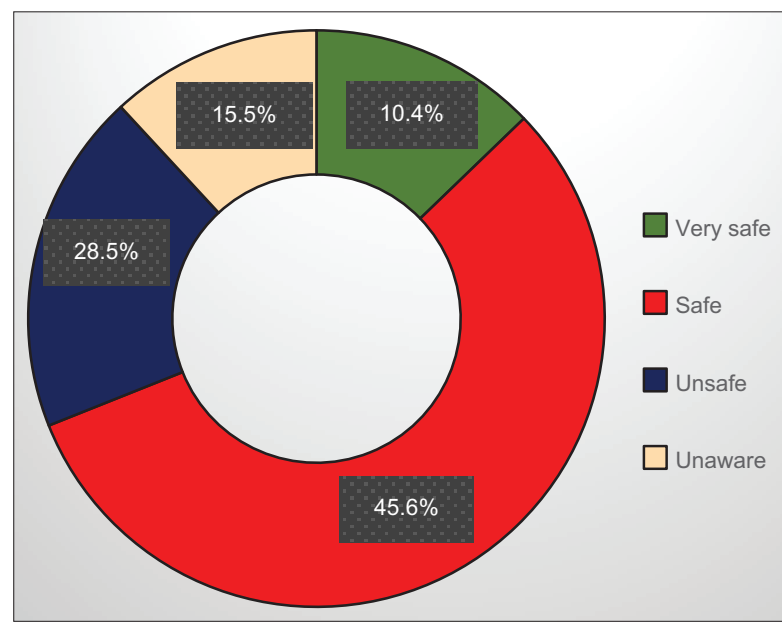

Fig. 2: Participants' knowledge regarding the safety of selfmedication practices 
Table 3: Attitude of the subjects' relating to the practice of self-medication

\begin{tabular}{lccc}
\hline \multirow{2}{*}{ Response } & \multicolumn{2}{l}{ Percentage } & \\
\cline { 2 - 4 } & Agree & Neutral & Disagree \\
\hline $\begin{array}{l}\text { Self-medication is a part of } \\
\text { self-care }\end{array}$ & 65.55 & 27.04 & 7.41 \\
$\begin{array}{l}\text { Self-medication can be } \\
\text { recommended to family and } \\
\text { friends }\end{array}$ & 50.74 & 31.48 & 17.78 \\
$\begin{array}{l}\text { Providing information regarding } \\
\text { various aspects of medicines while } \\
\text { dispensing is necessary }\end{array}$ & 58.89 & 30.74 & 10.37 \\
$\begin{array}{l}\text { Self-medication cannot be used in } \\
\text { both mild and serious conditions }\end{array}$ & 48.15 & 33.70 & 18.15 \\
$\begin{array}{l}\text { Simultaneous use of prescription } \\
\text { drugs with self-medicated products } \\
\text { can be potentially dangerous }\end{array}$ & 56.29 & 35.19 & 8.52 \\
$\begin{array}{l}\text { In case of side effects, physicians } \\
\text { help should be sought }\end{array}$ & 84.07 & 14.82 & 1.11 \\
$\begin{array}{l}\text { Self-treatment can hide disease } \\
\text { symptoms }\end{array}$ & 43.33 & 40.74 & 15.93 \\
\hline
\end{tabular}

\section{DISCUSSION}

Self-medication is the utilization of non-prescription medicines by individuals on their own initiative without any proficient medical supervision [16].

This study was conducted to evaluate the knowledge and attitude of self-medication practices among the residents of an urban community in Bengaluru.

In our study, the prevalence of self-medication was found to be $37.04 \%$ which was similar to the study conducted by Kulkarni et al. and Lal et al. which showed the prevalence of $30.7 \%$ and $31.3 \%$, respectively $[5,17]$. The previous studies conducted by Jain et al. and Kumar et al. among urban Indian population showed the prevalence of $73.6 \%$ and $92.8 \%$ which was contradictory to our study $[14,18]$. It is difficult to establish an association between different studies due to non-uniformity in the socioeconomic profiles and demographic traits of the population studied. Our study showed that the practice of self-medication was more common among the age group of 18-27 years which could be attributed to their increased utilization of online networking. A proportionately larger number of males (54.21\%) were self-medicating when compared to females (45.79\%) which was in contrast to the study conducted by Kasulkar et al. and Zafar et al. which had female predominance of $52.8 \%$ and $58.9 \%$, respectively $[8,13]$.

The study was categorized into domains of knowledge and attitude. The findings in the knowledge section revealed that 198 participants were already aware of the term "self-medication" and their main source of information regarding the practice of self-medication was obtained through acquaintances followed by media which was in contrast to the study conducted by Hussain and Khanum [19]. The most preferred system of medicine that could be used for self-mediation according to the participant's response was allopathy. This could be due to the widespread utilization of allopathic drugs and expanded data available regarding its usage in comparison with other systems of medicine. The study findings showed that the duration of time safe to practice self-medication was for few days followed by till the participants were relieved of symptoms. Most of the participants (45.6\%) found the practice of self-medication to be safe, whereas others $(28.5 \%)$ said that it is unsafe and minority $(15.1 \%)$ were unaware of the safety of self-medication which was compared to a study conducted by Bollu et al. where $78.1 \%$ considered the practice as safe, whereas $21.9 \%$ considered it unsafe [20]. The findings revealed that according to the knowledge of the participants, adults were considered as the safest population to practice self-medication. Three participants also responded that pregnant women were also considered safe to use self-medication which could be due to their lack of awareness regarding the risks associated with the usage of self-medication. It was observed that majority of our study population had a good knowledge regarding the side effects of self-prescribed medications. The reason for such awareness among the study population could be owed to their educational status. Majority of the subjects also stated that the impact of advertisements on self-medication was generally to a greater extent.

The next domain of our study is related to the attitude of the participants toward self-medication practices.

Majority of our participants agreed that self-medication is a vital component of self-care which was in accordance to a study conducted by Kumar et al. and Abay and Amelo [21,22]. A large proportion of the participants agreed that self-medication can be recommended to family and friends. The reason could be attributed to the availability of the previous prescription for similar ailments and confidence in self-diagnosis. The pharmacist is a bridge between the physicians and patients, who counsels and advices the patients to maximize the desired effect of the drugs and minimize the untoward reactions. The primary responsibility of the pharmacist is to check prescriptions from physicians before dispensing the medication to the patient to ensure that the patient does not receive the wrong drugs or an incorrect dose of the right medicine. It was found that most of the participants felt that it was necessary to provide information regarding various aspects of medicines while dispensing, whereas a minority disagreed to it which was in accordance to a study conducted by Bollu et al. where $85 \%$ of participants were interested in getting counseling from the dispensers [20]. In the population who disagreed to this fact, majority belonged to the age group of 28-37 years since they felt that it is the responsibility of only the physician to provide such counseling tips. The study revealed that majority of the respondents disapproved using self-medication for both mild and serious conditions. The basic duty of the pharmacist is related to the patient safety and wellbeing; therefore, the pharmacist makes sure that the patient is not prescribed a medication that might be allergic to or that will interact with food or another medication the patient is already taking. Although preventing dangerous drug interactions are primarily a physician's responsibility, pharmacists provide a check against this possibility. It was observed that of the participants had the opinion that simultaneous use of prescription drugs with self-medicated products could be potentially dangerous and majority of the participants agreed that physicians help should be sought in case of side effects. The possible explanation as to why such a huge population relies only on physicians is due to the oblivion regarding the services of clinical pharmacists and other health-care professionals in most of the developing countries. Majority of the respondents agreed to the fact that self-medication can hide disease symptoms. For example, fever itself is not an illness but a sign of one, most likely to be caused when the body is fighting an infection caused by a bacteria or virus. When the exact cause of fever is unknown, it is advised not to lower the elevated body temperature by taking an antipyretic medication (acetaminophen) before consultation. This can mask the symptoms, prolong the illness, and cause a delay in identification of the exact etiology.

Overall, our study population had a good knowledge and a positive attitude toward the practice of self-medication.

The study has its own limitations. Most of the study population belonged to the age group of 18-27 years, extending generalizations of our findings to population in other age groups is limited. The study was conducted for a short duration of time and access to health care like distance to health facilities or pharmacies were not addressed in this study.

\section{CONCLUSION}

Periodic studies on knowledge and perception of self-medication practices may give insight into the changing pattern of drug use in 
societies. This study mainly focuses on understanding the subjects' level of knowledge and attitude which will enable a more efficient process for creating awareness through holistic approaches among the public to ensure its safe and responsible use of self-medication.

\section{AUTHORS' CONTRIBUTIONS}

Sneha Suja Varghese and Sneha Dutta recruited the subjects, collected the data, and analyzed the results. Ann Mary Swaroop guided and supervised the work. All the authors equally contributed to the preparation of manuscript.

\section{CONFLICTS OF INTEREST}

The authors declare that they have no conflicts of interest.

\section{REFERENCES}

1. Gyawali S, Shankar PR, Poudel PP, Saha A. Knowledge, attitude and practice of self-medication among basic science undergraduate medical students in a medical school in Western Nepal. J Clin Diagn Res 2015;9:FC17-22

2. Saharan V, Pandey M. A study of prevalence of self-medication among people in Mumbai. Int J Pharm Sci 2015;7:253-6.

3. Frederick M, Wendy A, Robert H, Alabduljabbar M, Daniels C. The Role of Pharmacist in Self-care and Self-medication. Essential Medicines and Health Products Information Portal World Health Organization. Vol. 13. Report of the $4^{\text {th }}$ WHO Consultative Group on the Role of the Pharmacist; 1998.

4. Bennadi D. Self-medication: A current challenge. J Basic Clin Pharm 2013;5:19-23

5. Kulkarni PK, Khan MA, Chandrasekhar A. Self medication practices among urban slum dwellers in South Indian city. Int J Pharm Bio Sci 2012;3:81-7

6. Albawani SM, Hassan YB, Abd-Aziz N, Ganesan S. Self-medication practice among consumers in Sana'a city. Int J Pharm Pharm Sci 2016;8:119-24.

7. Sherazi BA, Mahmood KT, Amin F, Zaka M, Riaz M, Javed A. Prevalence and measure of self medication: A review. J Pharm Sci Res 2012;4:1774.

8. Zafar SN, Syed R, Waqar S, Zubairi AJ, Vaqar T, Shaikh M, et al.
Self-medication amongst university students of Karachi: Prevalence, knowledge and attitudes. J Pak Med Assoc 2008;58:214-7.

9. Hughes CM, McElnay JC, Fleming GF. Benefits and risks of self medication. Drug Saf 2001;24:1027-37.

10. Keshari SS, Kesarwani P, Mishra M. Prevalence and pattern of selfmedication practices in rural area of Barabanki. Indian J Clin Pract 2014;25:636-9.

11. Pranav V, Narayanan P, Guddattu V. Self medication practice among urban slum dwellers in Udupi taluk, Karnataka, India. Int J Pharm Pharm Sci 2017;9:19-23

12. Durgawale PM. Practice of self medication among slum-dwellers. Indian J Public Health 1998;42:53-5.

13. Kasulkar AA, Gupta M. Self medication practices among medical students of a private institute. Indian J Pharm Sci 2015;77:178-82.

14. Kumar V, Mangal A, Yadav G, Raut D, Singh S. Prevalence and pattern of self-medication practices in an urban area of Delhi, India. Med J Dr DY Patil Univ 2015;8:16.

15. Phalke VD, Phalke DB, Durgawale PM. Self-medication practices in rural Maharashtra. Indian J Community Med 2006;31:34.

16. Osemene KP, Lamikanra A. A study of the prevalence of self-medication practice among university students in Southwestern Nigeria. Trop J Pharm Res 2012;11:683-9.

17. Lal V, Goswami A, Anand K. Self-medication among residents of urban resettlement colony, New Delhi. Indian J Public Health 2007;51:249-51.

18. Jain M, Prakash R, Bapna D, Jain R. Prevalence and pattern of selfmedication practices in urban area of Southern Rajasthan. Natl J Community Med 2015;6:474-7.

19. Hussain A, Khanum A. Self medication among university students of Islamabad, Pakistan a preliminary study. South Med Rev 2008;1:14-6.

20. Bollu M, Vasanthi B, Chowdary PS, Chaitanya DS, Nirojini PS, Nadendla RR. Prevalence of self medication among the pharmacy students in Guntur: A questionnaire based study. World J Pharm Pharm Sci 2014;3:810-26.

21. Kumar N, Kanchan T, Unnikrishnan B, Rekha T, Mithra P, Kulkarni V, et al. Perceptions and practices of self-medication among medical students in coastal South India. PLoS One 2013;8:e72247.

22. Abay SM, Amelo W. Assessment of self-medication practices among medical, pharmacy, and health science students in Gondar University, Ethiopia. J Young Pharm 2010;2:306-10. 